\title{
Effect of thermal annealing and chemical treatments on secondary electron emission properties of atomic layer deposited MgO
}

Violeta Prodanovic', Hong Wah Chan, Anil U. Mane, Jeffrey W. Elam, Matthias M. Minjauw, Christophe Detavernier, Harry van der Graaf, and Pasqualina M. Sarro

Citation: Journal of Vacuum Science \& Technology A 36, 06A102 (2018); doi: 10.1116/1.5040813

View online: https://doi.org/10.1116/1.5040813

View Table of Contents: http://avs.scitation.org/toc/jva/36/6

Published by the American Vacuum Society

\section{Articles you may be interested in}

Atomic layer deposition of $\mathrm{Al}_{2} \mathrm{O}_{3}$ and $\mathrm{TiO}_{2}$ on $\mathrm{MoS}_{2}$ surfaces

Journal of Vacuum Science \& Technology A 36, 06A101 (2018); 10.1116/1.5043621

Hydrophobic surface modification of polymethyl methacrylate by two-dimensional plasma jet array at atmospheric pressure

Journal of Vacuum Science \& Technology A 36, 061302 (2018); 10.1116/1.5030718

Synthesis and characterization of titanium silicon oxide thin films prepared by plasma enhanced atomic layer deposition

Journal of Vacuum Science \& Technology A 36, 06A104 (2018); 10.1116/1.5043309

Electron-enhanced atomic layer deposition of silicon thin films at room temperature Journal of Vacuum Science \& Technology A 36, 01 A118 (2018); 10.1116/1.5006696

Rapid atomic layer etching of $\mathrm{Al}_{2} \mathrm{O}_{3}$ using sequential exposures of hydrogen fluoride and trimethylaluminum with no purging

Journal of Vacuum Science \& Technology A 36, 061508 (2018); 10.1116/1.5043488

Plasma-enhanced atomic layer deposition of titanium vanadium nitride

Journal of Vacuum Science \& Technology A 36, 06A103 (2018); 10.1116/1.5037463

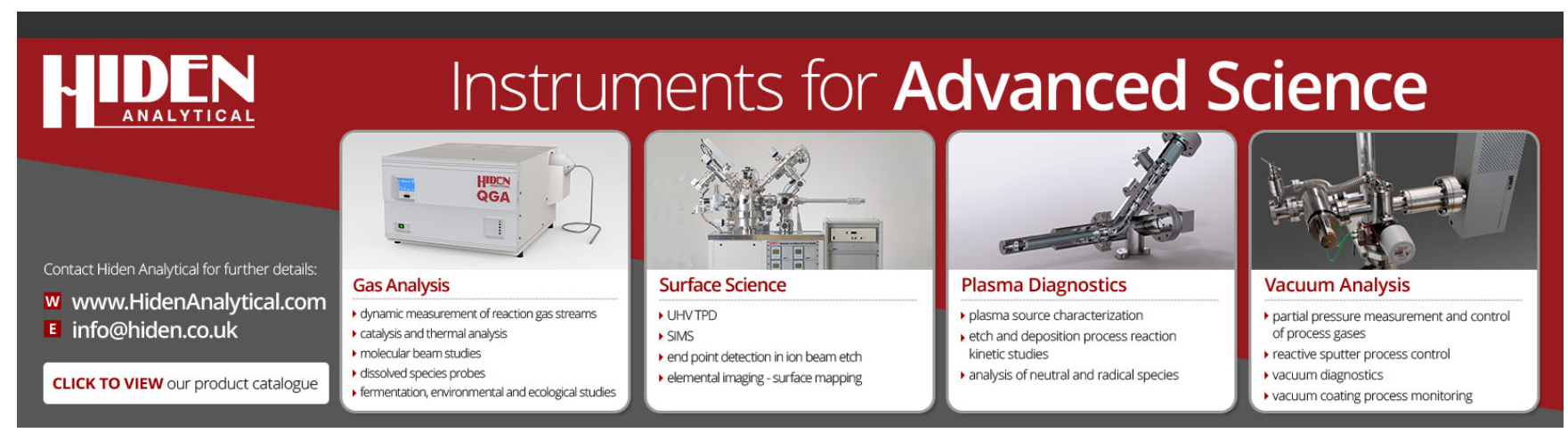




\title{
Effect of thermal annealing and chemical treatments on secondary electron emission properties of atomic layer deposited $\mathrm{MgO}$
}

\author{
Violeta Prodanović, ${ }^{1,2, a)}$ Hong Wah Chan, ${ }^{1,2, b)}$ Anil U. Mane, ${ }^{3, \mathrm{c})}$ Jeffrey W. Elam, ${ }^{3, \mathrm{~d})}$ \\ Matthias M. Minjauw, ${ }^{4, e)}$ Christophe Detavernier, ${ }^{4, f)}$ Harry van der Graaf, ${ }^{2, g)}$ and \\ Pasqualina M. Sarro ${ }^{1, h}$ ) \\ ${ }^{1}$ Electronic Components, Technology and Materials (ECTM), Delft University of Technology, Feldmannweg \\ 17, 2628 CT Delft, The Netherlands \\ ${ }^{2}$ National Institute for Subatomic Physics (Nikhef), Science Park 105, 1098 XG Amsterdam, The Netherlands \\ ${ }^{3}$ Energy Systems Division, Argonne National Laboratory, Argonne, Illinois 60439 \\ ${ }^{4}$ Department of Solid-State Physics, Ghent University, 9000 Ghent, Belgium
}

(Received 21 May 2018; accepted 7 September 2018; published 5 October 2018)

\begin{abstract}
This study reports on the secondary electron emission (SEE) performance of atomic layer deposited $\mathrm{MgO}$ films, with thicknesses in the range from 5 to $25 \mathrm{~nm}$, for the application in the Timed Photon Counter. In this novel, photodetector $\mathrm{MgO}$ is utilized as a material for the fabrication of ultrathin transmission dynodes (tynodes). Two different types of PECVD silicon oxide films are applied on top of $\mathrm{MgO}$, in order to protect it against etching steps in the fabrication of tynodes and also as a prevention against aging. Applicability of these two materials as capping films is evaluated in terms of achieved secondary electron yield (SEY) of $\mathrm{MgO}$ after their removal. Emission of secondary electrons is known to depend on numerous physical and chemical properties of the material, such as surface roughness and chemical composition. On that account, morphological and structural properties of modified $\mathrm{MgO}$ are determined by atomic force microscope and $\mathrm{x}$-ray photoelectron spectrometer and linked to the changes in SEE behavior. The authors demonstrate that the application of a suitable capping layer followed by its removal provides an SEY of 6.6, as opposed to the value of 4.8 recorded from the as-deposited $\mathrm{MgO}$ film. Furthermore, in a following experiment, they showed that annealing of $\mathrm{MgO}$ films at high temperatures (up to $1100{ }^{\circ} \mathrm{C}$ ) significantly improved the secondary electron emission, elevating the SEY to 7.2. Published by the AVS.

https://doi.org/10.1116/1.5040813
\end{abstract}

\section{INTRODUCTION}

Due to its wide bandgap $(\mathrm{Eg} \sim 7.8 \mathrm{eV})$, dielectric and refractory properties, as well as chemical and thermodynamic stability, $\mathrm{MgO}$ has been used in diverse applications, such as spintronics, where it proved to be a very efficient tunnel barrier in magnetic tunnel junctions. ${ }^{1}$ Recent work reports a high performance of this material for organic light emitting diode encapsulation. ${ }^{2}$ A notable role of $\mathrm{MgO}$ as a protective layer in plasma display panels (PDPs) is ascribed to its high ion-induced secondary electron emission (SEE) coefficient and antisputtering behavior in the presence of glow discharge plasma. ${ }^{3}$ These two material properties are crucial in providing low firing voltages and long lifetime of AC PDPs, respectively. Moreover, the SEE mechanism of $\mathrm{MgO}$ has been studied to investigate its applicability for other vacuum electronic devices where electron multiplication is required, ${ }^{4}$ such as in compact imaging detectors based on microchannel plate photomultiplier tubes. $^{5}$

\footnotetext{
${ }^{a)}$ Electronic mail: v.prodanovic@tudelft.nl

${ }^{\text {b) }}$ Electronic mail: h.w.chan@tudelft.nl

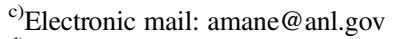

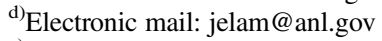

e)Electronic mail: matthias.minjauw@ugent.be

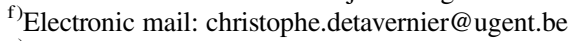

${ }^{\mathrm{g})}$ Electronic mail: h.vandergraaf@tudelft.nl

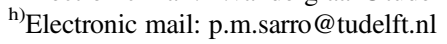

$\mathrm{MgO}$ has been deposited by various physical methods: sputtering, electron beam evaporation, molecular beam epitaxy, and pulsed laser deposition, but also chemical processes including spray pyrolysis, chemical vapor deposition, and sol-gel processes. A detailed overview of procedures to prepare $\mathrm{MgO}$ films is given in Ref. 6. In addition, atomic layer deposition (ALD), a thin film coating method which offers a high control over thickness and a conformal growth, has also been explored. ALD of $\mathrm{MgO}$ has been demonstrated by using different precursors and in a large temperature range. Most commonly used are cyclopentadienyl based magnesium precursors such as $\mathrm{Mg}(\mathrm{Cp})_{2}$ and $\mathrm{Mg}(\mathrm{CpEt})_{2}$, with $\mathrm{H}_{2} \mathrm{O}$ as an oxygen source. ${ }^{7-9}$ Alternatively, $\beta$-diketonate complex of magnesium ( $\mathrm{Mg}(\text { thd })_{2}$ ) in combination with ozone $\left(\mathrm{O}_{3}\right)$ or $\mathrm{H}_{2} \mathrm{O}_{2}$ can be employed. ${ }^{10}$

Here, we investigate the SEE properties of ALD MgO for application in the Timed Photon Counter (TiPC), a novel photodetector which utilizes a vertical stack of ultrathin membranes (tynodes) for electron multiplication in vacuum. ${ }^{11}$ Due to the significant reduction in size and weight of the device, as well as spatial and time resolution, TiPC will have a noteworthy role among existing photodetectors. ${ }^{12}$ Secondary electron yield (SEY) of MgO films prepared by various techniques is reported to be in the range from 2 to $22,{ }^{13,14}$ whereas ALD MgO exhibits the maximum SEY of $6.9 .^{5}$ This is, to our knowledge, the only available study on the electron-induced SEE from ALD MgO. ALD is 
chosen as the most convenient method for the growth of pinhole-free and conformal films of tynodes with thicknesses down to only $5 \mathrm{~nm}$. The fabrication method and results on SEE of ALD MgO tynodes have already been reported in our previous study. ${ }^{15}$ There we demonstrated that the surface composition of the investigated film changes throughout the deposition and etching steps required for the release of tynodes, which implies an alteration in SEE behavior compared to the as-deposited layer. Namely, electron emission is greatly affected by film properties such as roughness, stoichiometry, density, and conductivity. Additionally, it depends on the energy band structure, mainly bandgap energy and electron affinity, in view of which, a low or, preferably, negative electron affinity is a desired surface condition for enhanced SEE. ${ }^{16}$

In order to determine how the applied micromachining reflects on the SEE, the final steps in the fabrication of the tynodes are replicated on ALD MgO films deposited on an $\mathrm{Si}$ substrate, after which their reflective SEE is evaluated. Clearly, this approach only indicates if the transmission SEE (TSEE) of the tynodes is improved or reduced but does not directly provide a quantification of TSEE. Two different films, silicon oxides based on silane and tetraethoxysilane (TEOS), were used as capping layers for ALD MgO which is prone to water chemisorption when exposed to air. Moreover, this top film protects $\mathrm{MgO}$ from dissolving during unavoidable cleaning procedures in the MEMS processing. Next, the etching of the capping layer is performed in HF vapor to mimic the final tynode release step. Apart from the deposition and subsequent removal of the protection layer, $\mathrm{MgO}$ films are subjected to thermal treatments in the temperature range from 700 to $1100^{\circ} \mathrm{C}$. In addition to results on the SEE, the chemical and morphological characterization of $\mathrm{MgO}$ films is presented and brought into relation with their SEE properties.

\section{EXPERIMENT}

\section{A. Preparation of $\mathrm{MgO}$ films}

The $\mathrm{MgO}$ films are deposited on $525 \pm 15 \mu \mathrm{m}$ thick Si [100] substrates. Bis(cyclopentadienyl)magnesium $\left(\mathrm{Mg}(\mathrm{Cp})_{2}\right)$ and $\mathrm{H}_{2} \mathrm{O}$ are used as reactants for synthesizing $\mathrm{MgO}$ films in a hot wall ALD reactor at $200^{\circ} \mathrm{C}$ and pressure of 1.0 Torr. Each ALD cycle consists of $3 \mathrm{~s} \mathrm{Mg}(\mathrm{Cp})_{2}$ exposure, $15 \mathrm{~s} \mathrm{~N}_{2}$ purge, $1 \mathrm{~s} \mathrm{H}_{2} \mathrm{O}$ exposure, and $15 \mathrm{~s} \mathrm{~N}_{2}$ purge. Films of three different thicknesses $(5,15$, and $25 \mathrm{~nm})$ are prepared in processes with a growth rate of $0.1 \mathrm{~nm} /$ cycle. Storage of wafers under vacuum conditions, as a measure to prevent aging of material, started 5-7 days after the film growth (due to shipping from a deposition site to the location for further analysis). Unless stated otherwise, longer exposure of films to air is avoided prior to the following postprocessing and/or characterization.

The first step in a set of experiments was measurement of SEE of as-deposited films (experiment 1; Fig. 1). Next, two silicon oxide PECVD layers are employed for the encapsulation of $\mathrm{MgO}: \mathrm{SiO}_{\mathrm{x}}$ based on silane and tetraethylorthosilicate (TEOS), both deposited in a multichamber Concept One system (Novellus Inc.), at conditions listed in Table I. These

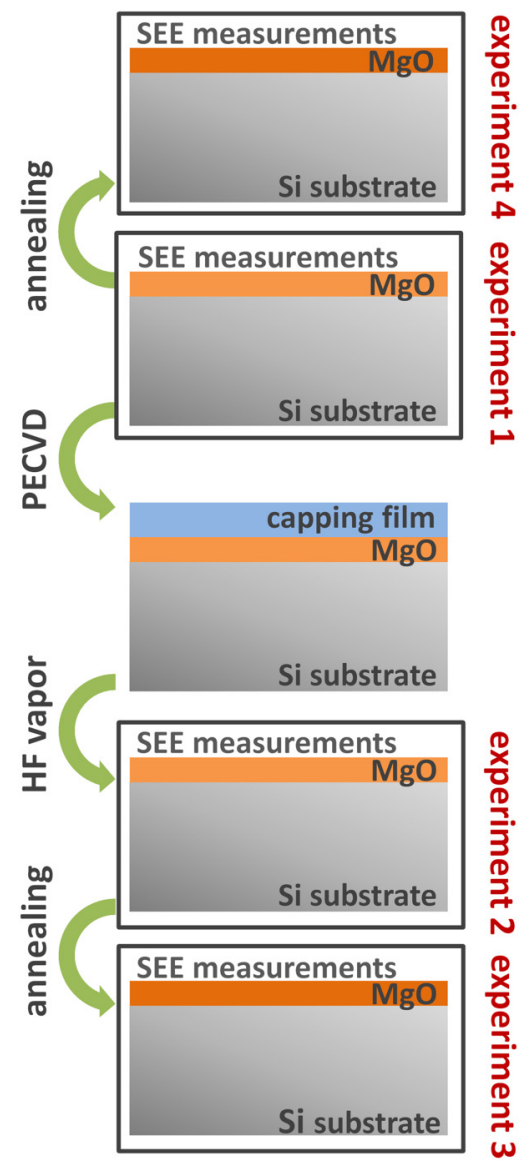

FIG. 1. Outline of the treatment and SEE characterization steps conducted in the study.

layers are chosen because of their easy removal in HF vapor, which, at the same time, maintains high selectivity toward $\mathrm{MgO}$. In experiment 2, SEE of the $\mathrm{MgO}$ film is quantified after the top film is removed in HF vapor by applying etching times of 10 and $40 \mathrm{~min}$ for silane and TEOS-based layers, respectively. The overetch (time interval in which $\mathrm{MgO}$ film is exposed to $\mathrm{HF}$ vapor) was not longer than 2-3 min in either case.

After this step, $\mathrm{MgO}$ films are subjected to an annealing step in a furnace under $\mathrm{N}_{2}$ ambient at 700,900 , or $1100{ }^{\circ} \mathrm{C}$ (experiment 3). Samples are heated up from a starting point of $600{ }^{\circ} \mathrm{C}$, with the rate of $10^{\circ} \mathrm{C} / \mathrm{min}$, and annealed at a set temperature for $2 \mathrm{~h}$. After cooling down to $600^{\circ} \mathrm{C}$, samples are unloaded from the furnace. In addition to experiments $1-3$, the effect of thermal annealing alone on the properties of $\mathrm{MgO}$ films is investigated in experiment 4, under the same

TABLE I. Process parameters for the deposition of films used for the encapsulation of $\mathrm{MgO}$.

\begin{tabular}{lcccc}
\hline \hline $\begin{array}{l}\text { Capping } \\
\text { film }\end{array}$ & $\begin{array}{c}\text { Composition } \\
\text { gasses }\end{array}$ & $\begin{array}{c}\text { Thickness } \\
(\mu \mathrm{m})\end{array}$ & $\begin{array}{c}\text { Deposition } \\
\text { temperature } \\
\left({ }^{\circ} \mathrm{C}\right)\end{array}$ & $\begin{array}{c}\text { Deposition } \\
\text { time } \\
(\mathrm{s})\end{array}$ \\
\hline $\mathrm{SiO}_{\mathrm{x}}$ & $\mathrm{SiH}_{4}, \mathrm{~N}_{2} \mathrm{O}$ & 1.0 & 400 & 120 \\
$\mathrm{TEOS}$ & $\mathrm{TEOS}, \mathrm{O}_{2}$ & 1.0 & 350 & 288 \\
\hline \hline
\end{tabular}


conditions applied in experiment 3. This series of steps is illustrated in Fig. 1, with indicated points at which SEE analysis is performed.

\section{B. Characterization methods}

X-ray photoelectron spectrometer (XPS) (K-Alpha by Thermo Scientific) is employed for the composition analysis of the $\mathrm{MgO}$ films. Apart from detection of binding energies on the surface, in-depth profiling by means of argon-ionsputtering has been performed as well. Wide scans were acquired using $200 \mathrm{eV}$ analyser pass energy and a $1 \mathrm{eV}$ step. High resolution spectra of the Mg 2p, Mg 1s, O 1s, C 1s, and $\mathrm{F} 1 \mathrm{~s}$ regions were recorded using $50 \mathrm{eV}$ pass energy and $0.1 \mathrm{eV}$ steps. Information on surface roughness is obtained from NTEGRA Aura by NT-MDT atomic force microscope (AFM). Scanning over $1 \times 1 \mu \mathrm{m}^{2}$ large area is performed in a tapping mode by using a silicon tip with a radius $10 \mathrm{~nm}$, height $14-16 \mu \mathrm{m}$, and Au-coated reflective side.

The SEE analysis of prepared films is performed with a special setup within a scanning electron microscope (SEM). Employed microscope (NovaNanoLab 650 Dual Beam, FEI) is provided with a continuous electron beam and operates at a vacuum level of $10^{-5}-10^{-6}$ mbar. The setup consists of a copper sample holder, in which the specimen is clamped, and a Teflon mounting block for electrical insulation of the holder and stage. The sample holder is connected via a feedthrough to a Keithley 2450 sourcemeter, which can apply a bias between -200 and $+200 \mathrm{~V}$, while simultaneously measuring the current. During the measurement of SEE, the sample is biased at $-50 \mathrm{~V}$, which ensures the repellence of all secondary electrons extracted from the sample surface. Apart from the true secondary electrons $(\mathrm{E}<50 \mathrm{eV})$, the backscattered electrons $(\mathrm{E}>50 \mathrm{eV})$ contribute to the measured current too. SEY is recorded for the primary electrons with energies from 0.2 to $2 \mathrm{keV}$, and actual landing energy is corrected by subtracting the sample bias. Two currents are monitored in the experiment: the one through sample $\left(\mathrm{I}_{\text {sample }}\right)$ and the other through primary beam current $\left(\mathrm{I}_{\mathrm{PE}}\right)$. The latter is measured with a Faraday cup placed inside the sample holder and varies from 20 to $160 \mathrm{pA}$ depending on the chosen electron energy. Formula for SEY is then given by $\mathrm{SEY}=1-\left(\mathrm{I}_{\text {sample }} / \mathrm{I}_{\mathrm{PE}}\right)$. Due to its insulating nature, $\mathrm{MgO}$ tends to charge-up under irradiation of an electron beam. Namely, near the film surface, a positively charged region is formed after the escape of secondary electrons, which affects the secondary electron measurement. ${ }^{17}$ In order to avoid charge-up and reduce the electron dose per surface unit, we operated SEM in a scan mode with a horizontal-field width of $2.56 \mathrm{~mm}$. To identify charge-up effects, we chose $20 \mathrm{~s}$-long scans at each energy of the primary beam since the effect is evident after measuring the current change throughout this time frame.

\section{RESULTS AND DISCUSSION}

\section{A. Chemical composition}

$\mathrm{MgO}$ films subjected to XPS analysis were stored under ambient conditions for about 8 weeks after the deposition and/or conducted treatments. First, we will evaluate the effect of HF vapor on the surface composition, after which the XPS data collected from the annealed $\mathrm{MgO}$ films will follow. $\mathrm{Mg} 2 \mathrm{p}$ spectra of a $5 \mathrm{~nm}$ thick $\mathrm{MgO}$ film which was encapsulated by silane-based oxide and subsequently released in HF vapor is presented in Fig. 2(a). The signal can be resolved into a major component from $\mathrm{MgO}$ at $50.0 \mathrm{eV}$ and a peak at $51.4 \mathrm{eV}$, which indicates the formation of a fluorine compound during the overetch time in HF vapor. Similar XPS profile is given in a report on $\mathrm{MgO}$ microspheres, ${ }^{18}$ where the binding of fluorine and magnesium

(a)

Mg 2p scan: $5 \mathrm{~nm}$ MgO + oxide (silane) + HF vapor

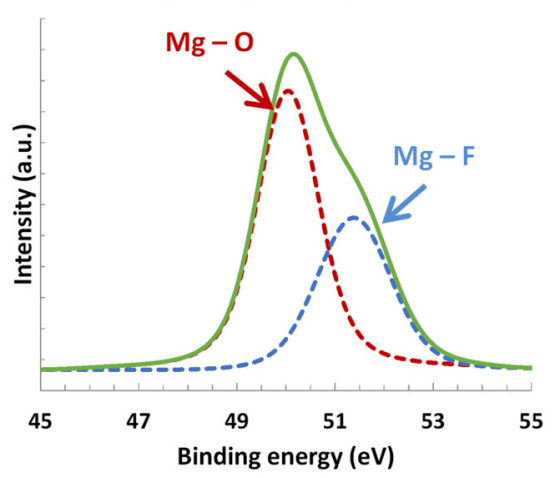

(b)

$$
5 \text { nm MgO + oxide (silane) }
$$

+ HF vapor

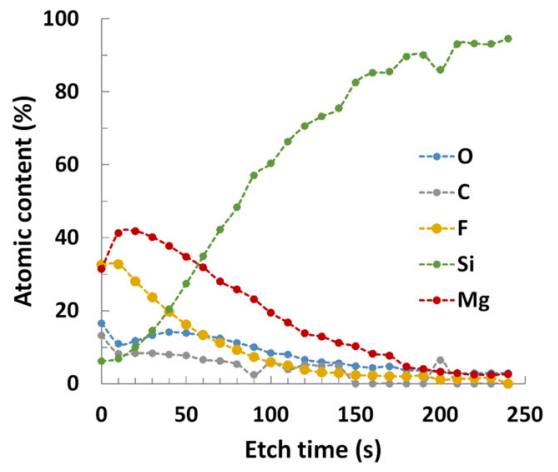

(c)

0 1s scan: $5 \mathrm{~nm} \mathrm{MgO} \mathrm{+} \mathrm{oxide}$ (silane) + HF vapor

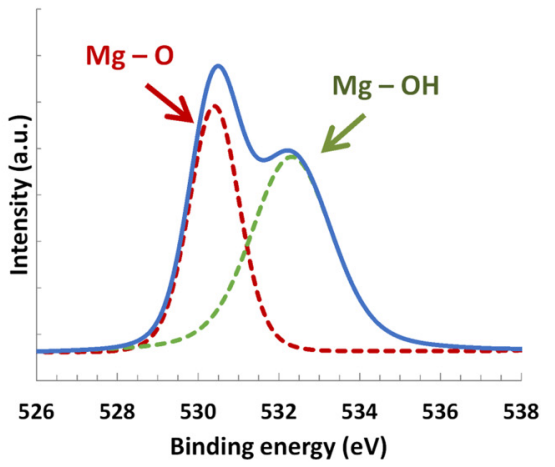

FIG. 2. XPS analysis of a $5 \mathrm{~nm}$ thick $\mathrm{MgO}$ film after encapsulation by silanebased oxide and its removal by HF vapor: (a) fitted $\mathrm{Mg} 2 \mathrm{p}$ spectra on the surface, (b) in-depth atomic content calculated after the etching of film by ion-sputtering, and (c) $\mathrm{O} 1 \mathrm{~s}$ spectra on the surface. 
atoms is verified by an $\mathrm{Mg} 2 \mathrm{p}$ component at $51.7 \mathrm{eV}$. Prominent F 1s signal in our study is present not only on the film surface but also in the bulk, as shown in Fig. 2(b).

The XPS analysis of as-deposited and thermally treated $\mathrm{MgO}$ films at 700 and $900^{\circ} \mathrm{C}$ showed that $\mathrm{O}$ 1s peak consists of two components [Figs. 2(c) and 3(a)-3(c)]. A major one occurs in the range from 531.1 to $532.3 \mathrm{eV}$ and is attributed to atoms of oxygen bonded to magnesium. The peak at higher binding energies (533.1-533.7 eV) originates from adsorbed hydroxyl groups, indicating that these samples were "aged" at the moment of XPS investigation. Different studies showed that a satellite peak in $\mathrm{O} 1 \mathrm{~s}$ signal arises already $1-2 \mathrm{~h}$ after the deposition of the $\mathrm{MgO}$ film. ${ }^{19,20}$

It can be noted that the contribution of the $\mathrm{Mg}(\mathrm{OH})$ peak is less pronounced in the film after the thermal treatment at $900^{\circ} \mathrm{C}$ [Fig. 3(c)], whereas the annealing of the $\mathrm{MgO}$ layer

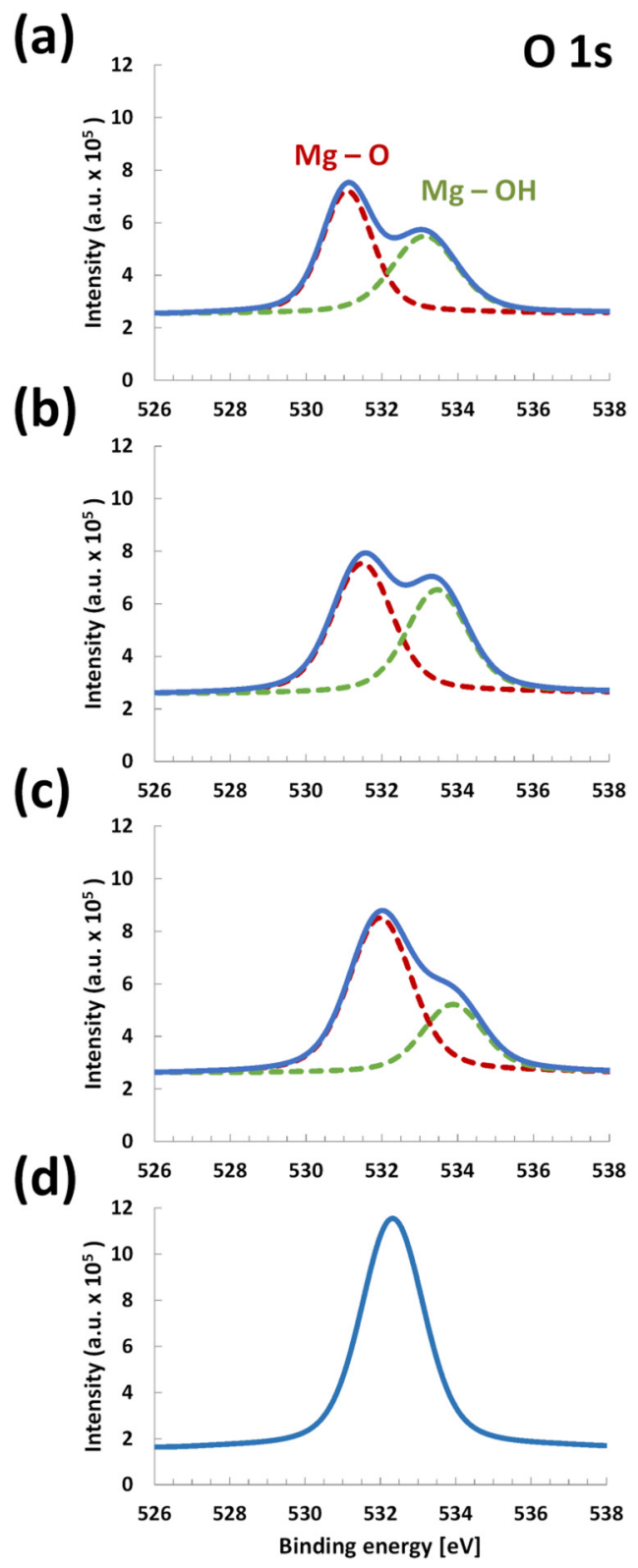

FIG. 3. Fitted $\mathrm{O} 1 \mathrm{~s}$ peak recorded on the surface of $25 \mathrm{~nm} \mathrm{MgO}$ thick films: (a) as-deposited; annealed at (b) $700{ }^{\circ} \mathrm{C}$, (c) $900{ }^{\circ} \mathrm{C}$, and (d) $1100^{\circ} \mathrm{C}$. at $1100{ }^{\circ} \mathrm{C}$ eliminated the $\mathrm{Mg}(\mathrm{OH})$ signal [Fig. 3(d)] and produced a nonhygroscopic surface. Survey of Si $2 p$ spectra in the bulk of the latter film [Fig. 4(d)] revealed the additional signal at $103.3 \mathrm{eV}$ which demonstrates the oxidation of $\mathrm{Si}$ substrate, similar to the results from $\mathrm{MgO}$ films subjected to a rapid thermal annealing. ${ }^{21}$ Growth of the interfacial layer caused by annealing at $1100^{\circ} \mathrm{C}$ can also be surmised from the change of the film color. Initially, the color of $\mathrm{MgO}$ could not be distinguished from the polished Si substrate, whereas the annealing produced a blue-shaded surface.

From the in-depth survey of relevant peaks, the atomic content in the same set of $\mathrm{MgO}$ films is calculated and plotted in Fig. 5. A rise of oxygen concentration in Figs. 5(b) and 5(c) suggests oxidation of $\mathrm{Si}$ substrate at

(a)

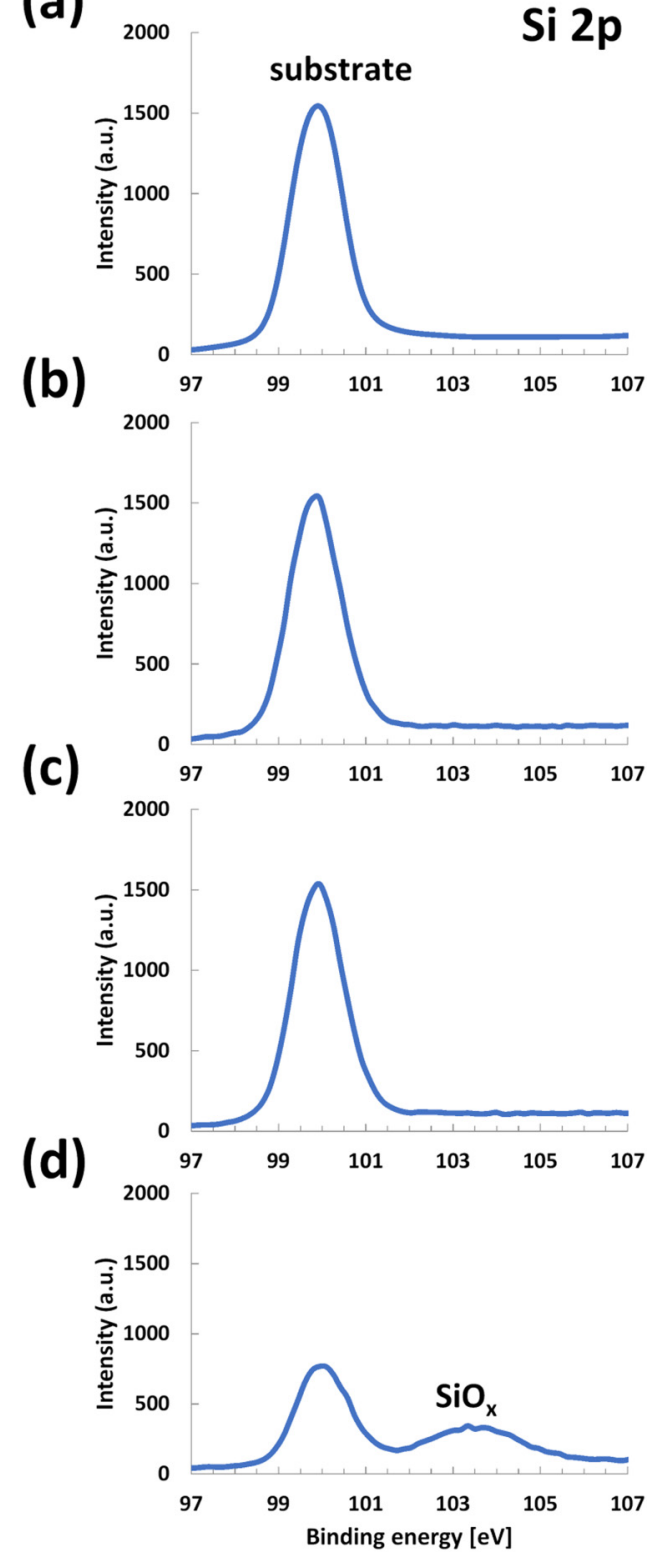

FIG. 4. Fitted in-depth Si $2 p$ signal recorded for $25 \mathrm{~nm} \mathrm{MgO}$ thick films on $\mathrm{Si}$ substrate: (a) as-deposited; annealed at (b) $700^{\circ} \mathrm{C}$, (c) $900^{\circ} \mathrm{C}$, and (d) $1100^{\circ} \mathrm{C}$. All peaks are recorded at the same etch level $(285 \mathrm{~s}$ after the ion-sputtering started). 
annealing temperatures of 700 and $900{ }^{\circ} \mathrm{C}$. Apart from the high carbon contamination level on the surface (15-20 at. \%), an amount of 5 at. \% of carbon is present in the bulk, most likely due to incomplete reaction with $\mathrm{H}_{2} \mathrm{O}$ which leaves some of the ligands on the surface. In this case, longer $\mathrm{H}_{2} \mathrm{O}$ exposure times or a higher deposition temperature would reduce the carbon content. Alternatively, the carbon may result from a thermal decomposition of the $\operatorname{Mg}(\mathrm{Cp})_{2}$ precursor employed for the ALD of $\mathrm{MgO}$, in which event suggested countermeasures are a lower deposition temperature or shorter $\operatorname{Mg}(\mathrm{Cp})_{2}$ exposure times. Due to the abovementioned oxidation of $\mathrm{Si}$ substrate and increase in the thickness of the film annealed at $1100^{\circ} \mathrm{C}$, a stronger $\mathrm{Si}$ signal is present near the surface and its rise is delayed in comparison with other samples. XPS data recorded for films treated with HF vapor prior to thermal annealing (experiment 2) show that fluorine content was eliminated by exposure to high temperatures (results not presented here).

\section{B. Surface morphology}

The AFM measurements of as-deposited $25 \mathrm{~nm}$ thick $\mathrm{MgO}$ films reveal a smooth and uniform surface. Root mean square (RMS) roughness extracted from the area shown in Fig. 6(a) is only $0.37 \mathrm{~nm}$. Due to a long exposure to atmospheric conditions (1-2 months), this sample already had $\mathrm{Mg}(\mathrm{OH})_{2}$ and $\mathrm{MgCO}_{3}$ formed on the surface but that does not seem to affect its smoothness. Deposition of a capping

(a)

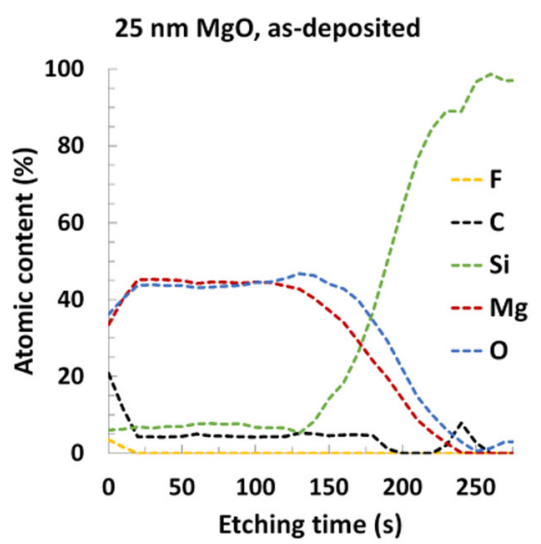

(c)

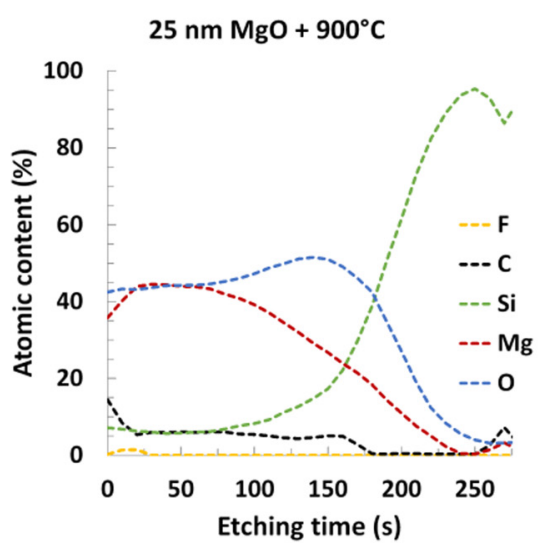

layer followed by its removal in HF vapor did not change the surface roughness (AFM image of this film is not included here and can be found in Ref. 15).

Next, the surface morphology is investigated for $\mathrm{MgO}$ samples that underwent thermal treatment. The surface roughness of $\mathrm{MgO}$ films annealed at $700{ }^{\circ} \mathrm{C}$ is similar to the one for as-deposited films with a value of $0.56 \mathrm{~nm}$ [Fig. 6(b)], whereas the annealing temperature of $900{ }^{\circ} \mathrm{C}$ increased the RMS to $1.30 \mathrm{~nm}$. The sample treated at $1100^{\circ}$ $\mathrm{C}$ exhibits a drastically changed surface morphology with an RMS of $9.15 \mathrm{~nm}$ and a grain size of $45 \mathrm{~nm}$.

The effect of annealing at $700{ }^{\circ} \mathrm{C}$ on the surface morphology of the HF-treated $\mathrm{MgO}$ film is presented in Fig. 6(e). Extracted RMS of $0.49 \mathrm{~nm}$ is similar to the as-deposited film subjected to annealing under the same conditions but with more than two times smaller grains. Data on RMS and grain size are summarized in Table II. For a better insight into the surface features, height profiles of films characterized by AFM are presented in Fig. 7. Plotted data are recorded over the center of $1 \times 1 \mu \mathrm{m}^{2}$ large scanned areas from Fig. 6 in the $\mathrm{x}$-direction.

\section{Secondary electron emission}

\section{Experiment 1: As-deposited and "aged" films}

A set of 5, 15, and $25 \mathrm{~nm}$ thick $\mathrm{MgO}$ films prepared by ALD is subjected to the SEE measurements by using the

(b)

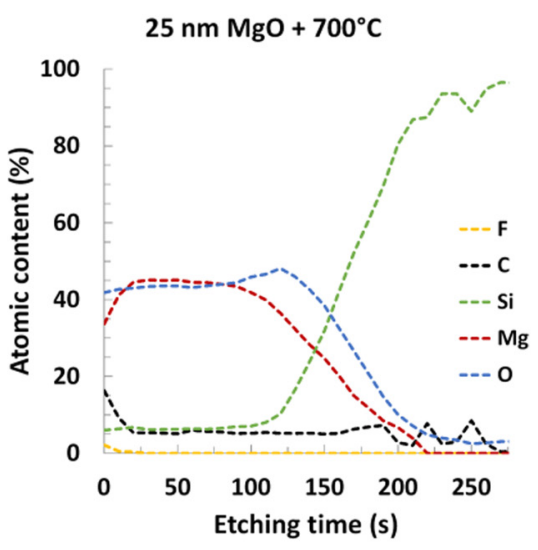

(d)

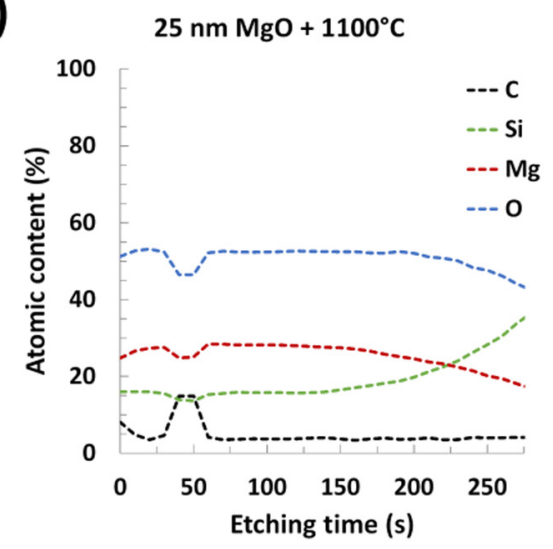

FIG. 5. In-depth atomic content of $\mathrm{MgO}$ films: (a) as-deposited and annealed at (b) $700{ }^{\circ} \mathrm{C}$, (c) $900{ }^{\circ} \mathrm{C}$, and (d) $1100{ }^{\circ} \mathrm{C}$. 
sample-biasing method. Samples were kept for up to 2 days in ambient conditions prior to this investigation. SEY strongly depends, among other properties, on the thickness of the material. It is demonstrated that the 5 and $15 \mathrm{~nm}$ thick $\mathrm{MgO}$ films exhibit a maximum SEY of 3.3 and 4, respectively, whereas the highest value of 4.8 is recorded for the $25 \mathrm{~nm}$ thick layer (Fig. 8). As expected, the energy of primary electrons at which the SEY peak occurs $\left(E_{\mathrm{PE}, \max }\right)$ shifts toward higher values as the thickness increases $\left(\mathrm{E}_{\mathrm{PE}}\right.$, max

(a)

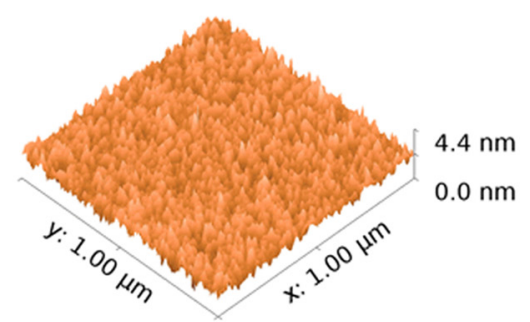

(b)

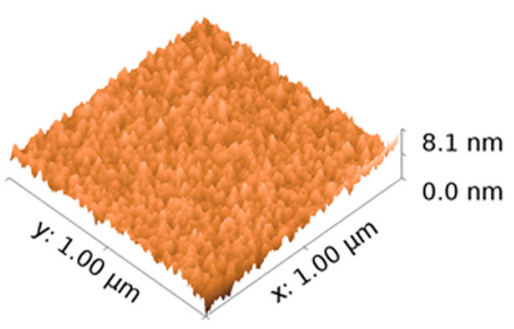

(c)

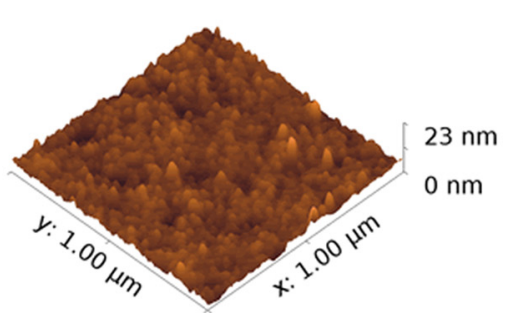

(d)

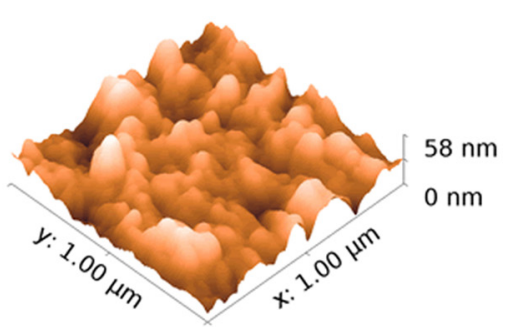

(e)

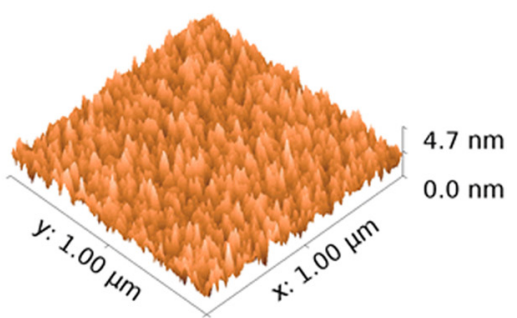

FIG. 6. AFM images of $25 \mathrm{~nm}$ thick $\mathrm{MgO}$ films: (a) as-deposited; and annealed at (b) $700{ }^{\circ} \mathrm{C}$, (c) $900{ }^{\circ} \mathrm{C}$, (d) $1100{ }^{\circ} \mathrm{C}$; (e) $\mathrm{HF}$ vapor-treated and annealed at $700{ }^{\circ} \mathrm{C}$. Surface investigation was performed 1-2 months after the deposition and/or thermal treatment. Samples were kept in the CR 100 environment prior to AFM analysis.
TABLE II. Morphology data obtained from AFM analysis of different $\mathrm{MgO}$ films with a thickness of $25 \mathrm{~nm}$.

\begin{tabular}{lcc}
\hline \hline MgO film & $\begin{array}{c}\text { RMS } \\
(\mathrm{nm})\end{array}$ & $\begin{array}{c}\text { Grain size } \\
(\mathrm{nm})\end{array}$ \\
\hline As-deposited & 0.37 & 6.5 \\
Annealing at $700^{\circ} \mathrm{C}$ & 0.56 & 13.8 \\
Annealing at $900^{\circ} \mathrm{C}$ & 1.30 & 28 \\
Annealing at $1100^{\circ} \mathrm{C}$ & 9.15 & 45 \\
10 min $\mathrm{HF}$ vapor + annealing at $700^{\circ} \mathrm{C}$ & 0.49 & 6.2 \\
\hline \hline
\end{tabular}

(a)

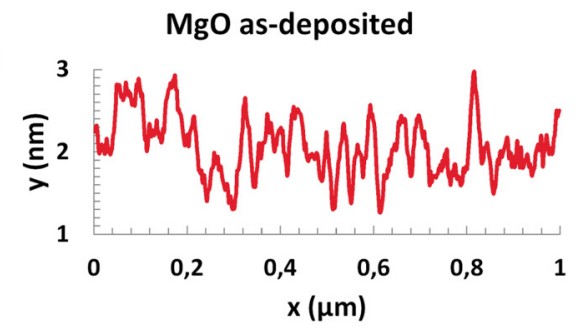

(b)

$\mathrm{MgO}+700^{\circ} \mathrm{C}$

(c)

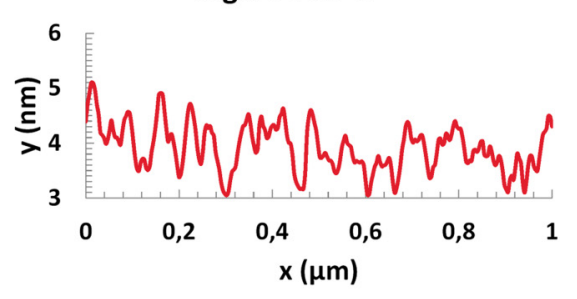

$\mathrm{MgO}+900^{\circ} \mathrm{C}$

(d)
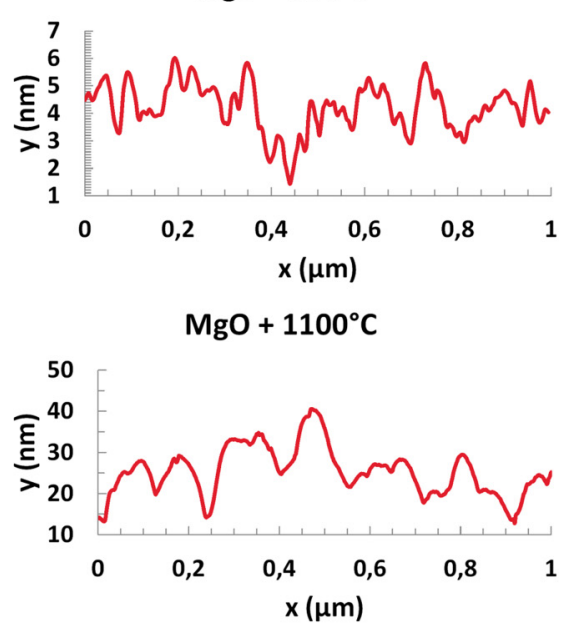

(e)

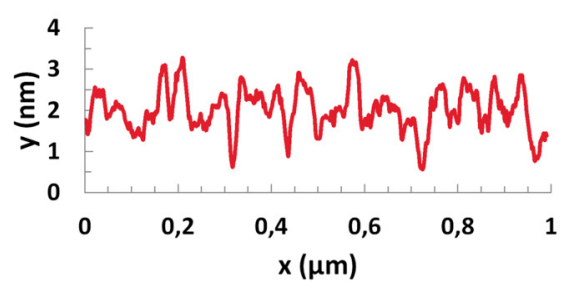

FIG. 7. Height profile of $\mathrm{MgO}$ films over the center $(\mathrm{y}=0.5 \mu \mathrm{m})$ of scanned area from Fig. 6, in the x-direction. (a) As-deposited; annealed at (b) $700{ }^{\circ} \mathrm{C}$, (c) $900{ }^{\circ} \mathrm{C}$, and (d) $1100^{\circ} \mathrm{C}$; (e) $\mathrm{HF}$ vapor-treated and annealed at $700^{\circ} \mathrm{C}$. 


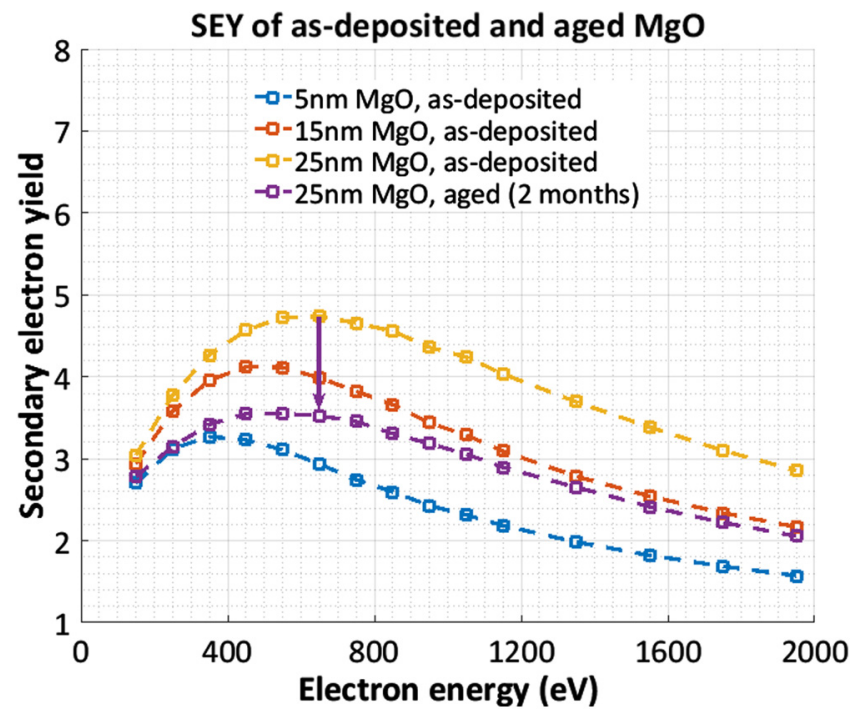

FIG. 8. SEY curves of as-deposited $\mathrm{MgO}$ films with different thicknesses and a remeasurement of a $25 \mathrm{~nm}$ thick layer 2 months after the first investigation. Energy of primary electrons is varied from 0.3 to $2 \mathrm{keV}$.

of 350,500 , and $600 \mathrm{eV}$ correspond to the 5, 15, and $25 \mathrm{~nm}$ thickness, respectively). Further improvement of the SEE performance by increasing the thickness is expected up to a point when it reaches the maximum escape depth. This quantity is a material property, which strongly depends on the film preparation, but the value of $41 \mathrm{~nm}$ reported in another study $^{22}$ is indeed higher than the thicknesses investigated here. However, due to the charging up, the method we employed is not suitable for the SEE measurements of thicker films, as a consequence of a continuous electron beam used in our SEM. Another study on ALD MgO films prepared in identical manner reveals similar effect of the thickness on SEE behavior ${ }^{23}$ but with slightly higher values than this work (5 nm thick MgO displays SEY of around 5). This divergence proves a strong dependence of SEY results on the measurement method.

A $25 \mathrm{~nm}$ thick $\mathrm{MgO}$ layer is remeasured approximately two months after the first SEE examination, after being stored under ambient conditions. As shown in Fig. 8, the maximum SEY of the "aged" film dropped to around 3.3, possibly due to the chemisorption of water and $\mathrm{CO}_{2}$ from the air.

\section{Experiment 2: Chemical treatments}

The two types of oxides are coated on top of as-deposited $\mathrm{MgO}$ films and removed after 2 month long storage by using $\mathrm{HF}$ vapor (experiment 2 in Fig. 1). SEE performances of $25 \mathrm{~nm} \mathrm{MgO}$ films after these treatments are shown in Fig. 9. In addition, we present a result from a film exposed only to $\mathrm{HF}$ vapor for $10 \mathrm{~min}$ without the preceding capping step. All performed surface modifications increased the SEY compared to the as-deposited layer, in the range from 5.6 to 6.6. The surface morphology of HF-treated $\mathrm{MgO}$ has not significantly changed in comparison to the as-deposited film. ${ }^{15}$

Since the only verified difference in chemical composition is the presence of fluorine peak [Figs. 2(a) and 2(b)], the improvement of SEY is attributed to this factor.

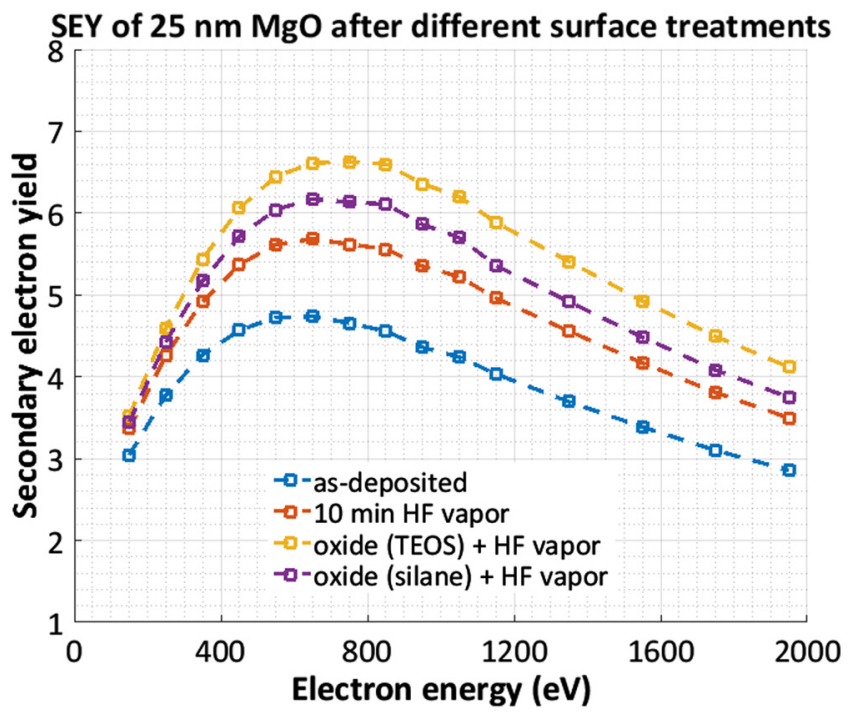

FIG. 9. SEY-E $\mathrm{PE}_{\mathrm{P}}$ curves of $25 \mathrm{~nm}$ thick $\mathrm{MgO}$ films after removal of the encapsulation layers in HF vapor and after exposure to HF vapor alone (the third plot from top to bottom).

Etching time of the as-deposited $\mathrm{MgO}$ in $\mathrm{HF}$ vapor seems not to affect the SEE, and the same result is obtained after 5 and 10 min long cycle (only one curve is plotted in Fig. 9). Results obtained from films with a thickness of $15 \mathrm{~nm}$ display the same trend: deposition and removal of the capping layer provide higher SEY than HF vapor etching solely. Furthermore, the TEOS-based oxide proved to be a better choice for the capping of $\mathrm{MgO}$. The reason behind this is not clear to this date, but one of the influencing factors may be a soak time of the wafer at the temperature of $350^{\circ} \mathrm{C}$, prior to the PECVD of TEOS-based oxide. This 2 min long step, involving the gas-purging, is introduced in the chamber of the system to reduce defects in the growing film. In our case, it probably removes the contamination from the $\mathrm{MgO}$ film, producing a "cleaner" surface after the removal of PECVD material. Finally, these results show that the encapsulation provides SEY two times greater than a film stored in air for the same amount of time (remeasured $\mathrm{MgO}$ film in Fig. 8).

\section{Experiments 3 and 4: Thermal annealing}

The SEE behavior of $\mathrm{MgO}$ films with different thicknesses after annealing at $700^{\circ} \mathrm{C}$ is presented in Fig. 10. For a better visual guidance, results from the as-deposited films are included in the same graph. Improvement of the SEY is confirmed for all films, with the highest yield of 6.4 recorded for $25 \mathrm{~nm}$ thick $\mathrm{MgO}$. Next, the set of samples presented in Fig. 9 was subjected to the thermal treatment at $700{ }^{\circ} \mathrm{C}$. The outcome, as illustrated in Fig. 11, is almost identical curves of all three films that have been exposed to HF vapor. These samples exhibit somewhat lower SEY of around 5.8, as compared to 6.4 obtained after annealing of the as-deposited sample. XPS data of these films (not included here) show the absence of the fluorine signal. Most likely, these films sustained a different modification in morphology due to the initial presence of the fluorine compound on the surface, as 


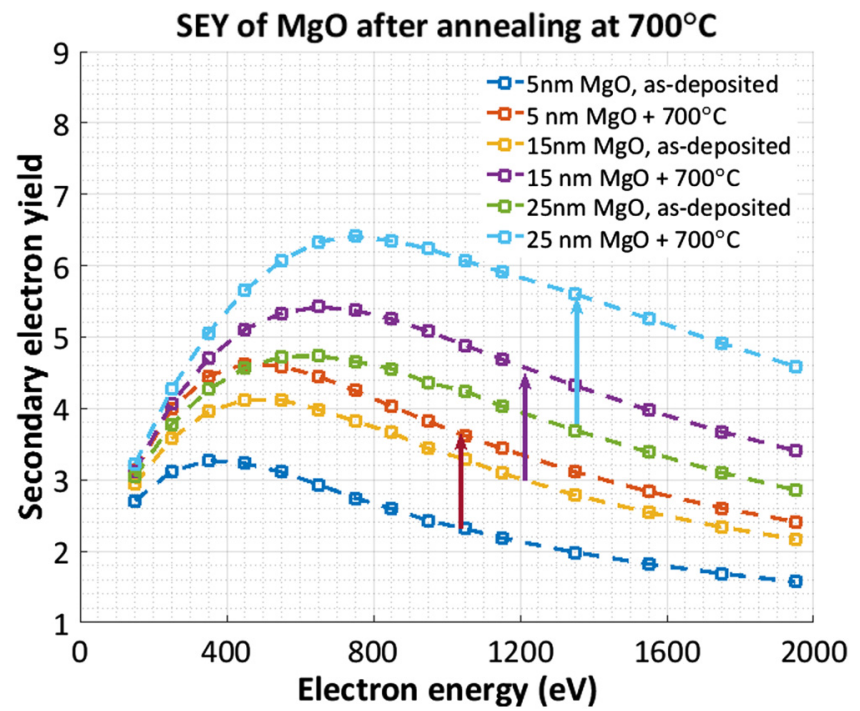

Fig. 10. Effect of annealing at $700{ }^{\circ} \mathrm{C}$ on SEE of $\mathrm{MgO}$ films with different thicknesses.

shown in Figs. 6(b) and 6(e). Emission of secondary electrons is less efficient from the equally rough surface with smaller grains, with the SEY of 5.8 and 6.4 for the grain size of 6.2 and $13.8 \mathrm{~nm}$, respectively. Opposite trend is reported by $\mathrm{Vaz},{ }^{24}$ where diamond surfaces with a (several orders of magnitude) reduced grain size exhibited higher SEY. Therefore, a further analysis on the chemical composition of $\mathrm{HF}$ vapor-treated and annealed $\mathrm{MgO}$ films is required to interpret this result.

Impact of annealing at higher temperatures (900 and $1100^{\circ}$ C) on the SEE performance of $25 \mathrm{~nm}$ thick $\mathrm{MgO}$ films is shown in Fig. 12. The maximum yield of 7.25 is measured from the film annealed at $900^{\circ} \mathrm{C}$, which is the highest SEY value in this study. However, a deviation in the tail of this curve is an evidence of a charge-up occurring in the film during the measurement. This is probably the side effect of

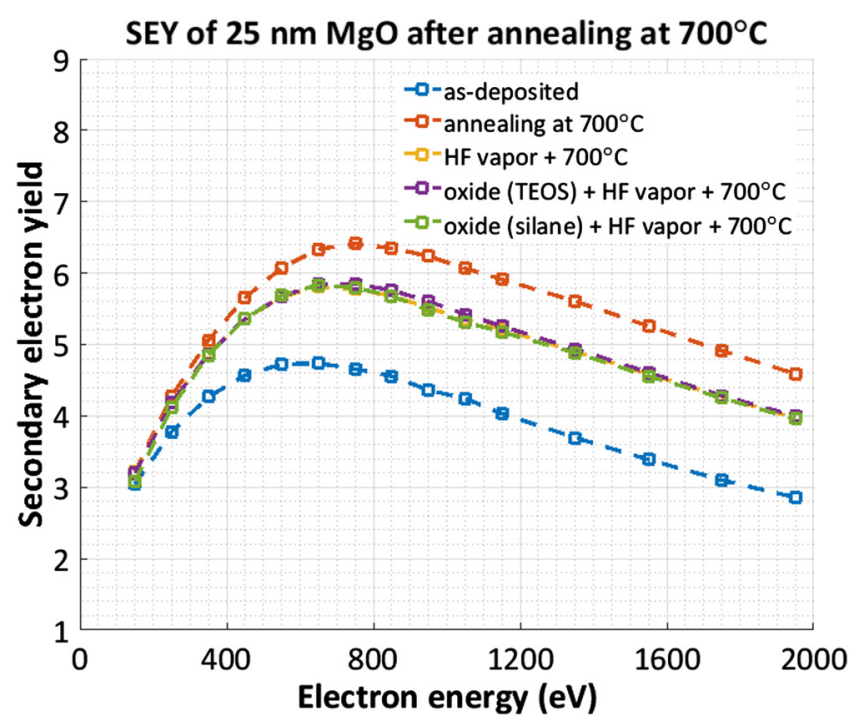

FIG. 11. SEY of $25 \mathrm{~nm}$ thick $\mathrm{MgO}$ films submitted to different chemical treatments and subsequent annealing at $700^{\circ} \mathrm{C}$.

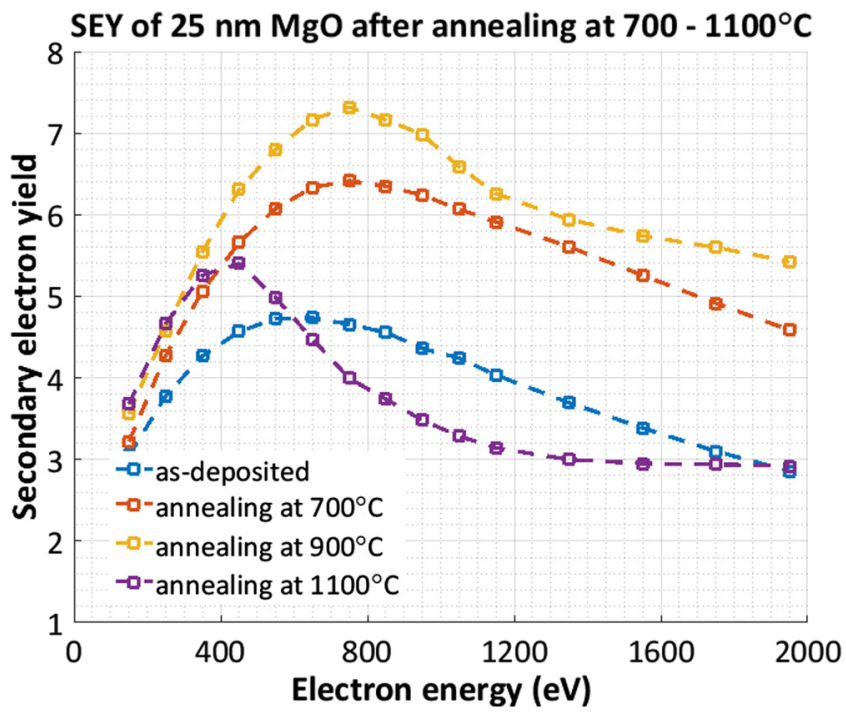

FIG. 12. SEY of $25 \mathrm{~nm}$ thick films after annealing in the temperature range from 700 to $1100^{\circ} \mathrm{C}$.

initialized growth of interfacial silicon-suboxides [as suggested by the increase of $\mathrm{O}$ 1s signal in Fig. 5(c)] which increased the thickness of investigated film and hindered the electron supply from $\mathrm{Si}$ substrate to the electron-emitting surface. The effect of thickness of the $\mathrm{MgO}$ film on its SEE properties is discussed in the study by Lee et $a .^{25}$ Charge-up is even more severe for the sample annealed at $1100^{\circ} \mathrm{C}$, for which the abrupt increase of thickness is demonstrated by both the presence of $\mathrm{SiO}_{\mathrm{x}}$ peak [Fig. 4(d)] and a higher oxygen content at the surface [Fig. 5(d)]. Therefore, the SEYs of films annealed at 900 and $1100{ }^{\circ} \mathrm{C}$ could not be accurately established and are expected to differ from the values plotted in Fig. 12.

Comparison of SEY of as-deposited $\mathrm{MgO}$ to films annealed at 700 and $900{ }^{\circ} \mathrm{C}$ only in terms of morphology parameters suggests the increase of SEY with the grain size. This result is not in line with reports by Dzhanoev et al. ${ }^{26}$ and Burton et al. ${ }^{27}$ where the presence of larger grains on the flat surface and increased roughness induced the degradation of SEE. However, to attribute SEY increase to grain size increase alone would be a misleading conclusion because of the varying composition of materials investigated in this work.

\section{SUMMARY AND CONCLUSIONS}

$\mathrm{MgO}$ films grown on silicon by ALD, with thicknesses in the range from 5 to $25 \mathrm{~nm}$, have been subjected to different chemical and temperature treatments to improve the SEE performance, for their application in the Timed Photon Counter. A study on the morphology and chemical composition of various $\mathrm{MgO}$ films is carried out in order to relate the measured SEE to material properties. First, $\mathrm{MgO}$ films underwent treatments which mimic the final steps in the fabrication of ultrathin membranes (tynodes) for electron multiplication. As a protection against processing steps in the release of the tynodes, we applied two types of PECVD materials as encapsulation layers, silane and TEOS-based oxide, which are then removed by HF vapor etching. After the release, 
$\mathrm{MgO}$, now with a modified surface, is analyzed in terms of SEE by using a sample-biasing method inside the SEM. Increased SEY of the treated $\mathrm{MgO}$, compared to as-deposited films, is demonstrated. TEOS-based oxide turned out to be a more beneficial capping film, providing the elevation of the maximum SEY from 4.8 to 6.6 for $25 \mathrm{~nm}$ thick films. This phenomenon is not completely clear and may originate from the top layer with a fluorine content. In that case, the compound formed on the surface has a higher SEY than pure $\mathrm{MgO}$. Moreover, storage of $\mathrm{MgO}$ films with a capping layer on top proved to prevent the deterioration of SEY exhibited by $\mathrm{MgO}$ films kept in air without encapsulation. In addition, we performed annealing of $\mathrm{MgO}$ at high temperatures and validated that this also improved the SEE performance. In this set of samples, the highest SEY of 7.25 was recorded after annealing of $25 \mathrm{~nm}$ thick $\mathrm{MgO}$ at $900^{\circ} \mathrm{C}$. AFM scanning revealed a drastic change of surface morphology after the annealing steps, whereas XPS data suggest the formation of $\mathrm{SiO}_{\mathrm{x}}$ interfacial films. As future work, an examination of the electron affinity (or other properties related to the energy band of material) is suggested for a better understanding on how surface and composition modifications affect the SEE of thin $\mathrm{MgO}$ films.

\section{ACKNOWLEDGMENTS}

This work is supported by the ERC-Advanced Grant 2012 MEMBrane 320764. The authors would like to thank the staff of Else Kooi Laboratory (EKL) and the Department of Imaging Physics at TU Delft for all the help provided in the conduction of this experiment.

${ }^{1}$ Z. Diao et al., Appl. Phys. Lett. 90, 132508 (2007).

${ }^{2}$ M. Li, M. Xu, J. Zou, H. Tao, L. Wang, Z. Zhou, and J. Peng, Nanotechnology 27, 494003 (2016).

${ }^{3}$ J. P. Boeuf, J. Phys. D: Appl. Phys. 36, R53 (2003).

${ }^{4}$ S. X. Tao, H. W. Chan, and H. van der Graaf, Materials 9, 1017 (2016).

${ }^{5}$ A. U. Mane et al., Phys. Procedia 37, 722 (2012).
${ }^{6}$ A. M. E. Raj, M. Jayachandran, and C. Sanjeeviraja, CIRP J. Manuf. Sci. Technol. 2, 92 (2010).

${ }^{7}$ M. Putkonen, T. Sajavaara, and L. Niinistö, J. Mater. Chem. 10, 1857 (2000).

${ }^{8}$ B. B. Burton, D. N. Goldstein, and S. M. George, J. Phys. Chem. C 113, 1939 (2009).

${ }^{9}$ S. Vangelista, R. Mantovan, A. Lamperti, G. Tallarida, B. KutrzebaKotowska, S. Spiga, and M. Fanciulli, J. Phys. D: Appl. Phys. 46, 485304 (2013).

${ }^{10}$ M. Putkonen, L.-S. Johansson, E. Rauhala, and L. Niinistö, J. Mater. Chem. 9, 2449 (1999).

${ }^{11}$ H. van der Graaf et al., Nucl. Instrum. Methods Phys. Res. Sect. A 847, 148 (2017).

${ }^{12}$ Y. Bilevych, S. E. Brunner, H. W. Chan, S. X. Tao, and H. van der Graaf, Nucl. Instrum. Methods Phys. Res. Sect. A 809, 171 (2016).

${ }^{13}$ N. R. Whetten and A. B. Laponsky, J. Appl. Phys. 28, 515 (1957).

${ }^{14}$ J. Li, W. Hu, Q. Wei, S. Wu, X. Hua, and J. Zhang, J. Electron. Mater. 46, 1466 (2017).

${ }^{15}$ V. Prodanović, H. W. Chan, A. U. Mane, J. W. Elam, H. van der Graaf, and P. M. Sarro, Proceedings of the 2017 IEEE 30th International Conference on Micro Electro Mechanical Systems (MEMS), Las Vegas, 22-26 January 2017 (IEEE, 2017), p. 740.

${ }^{16}$ S. X. Tao, A. Theulings, J. Smedley, and H. van der Graaf, Diamond Relat. Mater. 53, 52 (2015).

${ }^{17}$ A. Chvyreva and A. J. M. Pemen, IEEE Trans. Dielectr. Electr. Insul. 21, 2274 (2014).

${ }^{18}$ L.-X. Li, D. Xu, X.-Q. Li, W.-C. Liu, and Y. Jia, New J. Chem. 38, 5445 (2014).

${ }^{19}$ S. Altieri, L. H. Tjeng, and G. A. Sawatzky, Phys. Rev. B 61, 16948 (2000).

${ }^{20}$ L. Savio, E. Celasco, L. Vattuone, and M. Rocca, J. Phys. Chem. B 108, 7771 (2004)

${ }^{21}$ H.-L. Lu, S.-J. Ding, and D. W. Zhang, Electrochem. Solid-State Lett. 13, G25 (2010).

${ }^{22}$ N. R. Rajopadhye, V. A. Joglekar, V. N. Bhoraskar, and S. V. Bhoraskar, Solid State Commun. 60, 675 (1986).

${ }^{23}$ S. J. Jokela, I. V. Veryovkin, A. V. Zinovev, J. W. Elam, A. U. Mane, Q. Peng, and LAPPD Collaboration, Phys. Procedia 37, 740 (2012).

${ }^{24}$ R. Vaz, P. W. May, N. A. Fox, C. J. Harwood, V. Chatterjee, J. A. Smith, C. J. Horsfield, J. S. Lapington, and S. Osbourne, J. Instrum. 10, P03004 (2015).

${ }^{25}$ J. Lee, T. Jeong, S. Yu, S. Jin, J. Heo, W. Yi, D. Yeon, and J. M. Kim, Appl. Surf. Sci. 174, 62 (2001).

${ }^{26}$ A. R. Dzhanoev, F. Spahn, V. Yaroshenko, H. Lühr, and J. Schmidt, Phys. Rev. B 92, 125430 (2015).

${ }^{27}$ T. S. Burton, T. C. Back, S. B. Fairchild, and G. B. Thompson, J. Vac. Sci. Technol. A 35, 041404 (2017). 